\title{
Tulane
}

\author{
Tulane Economics Working Paper Series
}

\section{Expanding the Theory of Tax Compliance from Individual to Group Motivations}

\author{
James Alm \\ Department of Economics \\ Tulane University \\ New Orleans, LA \\ jalm@tulane.edu \\ Working Paper 1309 \\ February 2013
}

\begin{abstract}
Taxpayers face well-known and well-identified individual motivations in their compliance decisions, motivations that originate with the standard economic model of tax evasion in which financial incentives are shaped by audit, penalty, and tax rates. However, there is growing evidence that these individual incentives, while important, are not always decisive. Individuals do not always behave as the selfish, rational, self-interested individuals portrayed in the standard neoclassical paradigm, but rather are often motivated by many other factors that have as their main foundation some aspects of social norms, morality, altruism, fairness, or the like, factors that I broadly and no doubt imprecisely lump together as group motivations. I argue that the compliance puzzle can be explained, at least in part, by expanding the standard analysis of individual compliance behavior to incorporate the important ways in which individual decisions are shaped by group motivations. I also provide empirical and experimental evidence to support these arguments, and, I suggest-and predict-some promising lines of future research.
\end{abstract}

Keywords: Tax evasion, behavioral economics, experimental economics JEL: H2, H26, D03, C9 


\title{
Expanding the Theory of Tax Compliance from Individual to Group Motivations
}

\author{
James Alm*
}

\begin{abstract}
Taxpayers face well-known and well-identified individual motivations in their compliance decisions, motivations that originate with the standard economic model of tax evasion in which financial incentives are shaped by audit, penalty, and tax rates. However, there is growing evidence that these individual incentives, while important, are not always decisive. Individuals do not always behave as the selfish, rational, self-interested individuals portrayed in the standard neoclassical paradigm, but rather are often motivated by many other factors that have as their main foundation some aspects of social norms, morality, altruism, fairness, or the like, factors that I broadly and no doubt imprecisely lump together as group motivations. I argue that the compliance puzzle can be explained, at least in part, by expanding the standard analysis of individual compliance behavior to incorporate the important ways in which individual decisions are shaped by group motivations. I also provide empirical and experimental evidence to support these arguments, and, I suggest - and predict - some promising lines of future research.
\end{abstract}

Keywords Tax evasion, behavioral economics, experimental economics.

JEL Classifications H2, H26, D03, C9.

\footnotetext{
* Department of Economics, Tulane University, 6823 St. Charles Avenue, 208 Tilton Hall, New Orleans, LA 70118-5698 (telephone +1 504862 8344; fax +1 504865 5869; email jalm@tulane.edu). This paper is based on my keynote address at the Annual Conference of the Italian Society of Public Economists (SIEP), "Informal Economy, Corruption, and Tax Evasion", held in Pavia, Italy, in September 2012. I am indebted to Michele Bernasconi, Francesco Forte, and Alessandro Santoro for helpful comments and discussions.
} 


\section{Introduction}

There is widespread evidence that tax evasion - or illegal and intentional actions to reduce legally due tax obligations - is commonplace in nearly all countries (Schneider and Enste, 2002). Still, the puzzle of tax compliance is not why there is so much cheating, but why there is so little. Typically, the percent of all individual income tax returns that are audited is well less than one percent, and the penalties on even fraudulent evasion are only a fraction of unpaid taxes. Virtually all economic models of taxpayer behavior conclude that there should be much more tax evasion than is actually observed. However, most people pay most of their taxes most of the time. The puzzle of tax compliance is to explain why people pay taxes.

In this paper I argue that this compliance puzzle can be explained, at least in part, by expanding the standard analysis of individual compliance behavior to incorporate the important ways in which individual decisions are shaped by group motivations. Taxpayers face well-known and well-identified individual motivations in their compliance decisions, motivations that originate with the standard economic model of tax evasion in which financial incentives are shaped by audit, penalty, and tax rates. However, there is growing evidence that these individual incentives, while important, are not always decisive. Individuals do not always behave as the selfish, rational, self-interested individuals portrayed in the standard neoclassical paradigm, but rather are often motivated by many other factors that have as their main foundation some aspects of social norms, morality, altruism, fairness, or the like, factors that I broadly and no doubt imprecisely lump together as group motivations. I argue that it is not possible to understand fully an individual's compliance decisions without considering in some form these group dimensions and their implications for individual behavior. I also provide empirical and experimental 
evidence to support these arguments, and I suggest some promising lines for future research.

\section{The Traditional Approach: Emphasizing Individual}

\section{Motivations}

The basic theoretical model used in nearly all research on tax compliance begins with the economics-of-crime model, first applied to tax compliance by Allingham and Sandmo (1972). Here a single representative individual is viewed as maximizing the expected utility of the tax evasion gamble, rationally weighing the benefits of successful cheating against the risky prospect of detection and punishment, and the individual pays taxes because he or she is afraid of getting caught and penalized if he or she does not report all income. ${ }^{1}$

To illustrate this "portfolio" approach more precisely, consider a simplified form of the standard model. A representative individual is assumed to receive a fixed amount of income $I$, and must choose how much of this income to report to the tax authorities and how much to underreport. The individual pays taxes at rate $t$ on every dollar $R$ of income that is reported, while no taxes are paid on underreported income. However, the individual may be audited with a fixed probability $p$; if audited, then all underreported income is discovered, and the individual must pay a penalty at rate $f$ on each dollar that he or she was supposed to pay in taxes but did not pay. The individual's income $I_{C}$ if caught underreporting equals $I_{C}=I-t R-f[t(I-R)]$, or income less taxes paid on reported income less penalties on unreported taxes; if underreporting is not caught, income $I_{N}$ is $I_{N}=I-t R$, or income less taxes paid on reported income. The individual is assumed to choose reported income to maximize expected utility, or $E U(I)=p U\left(I_{C}\right)+(1-p) U\left(I_{N}\right)$, where $E$ is

\footnotetext{
1 For recent discussions of much of this literature, see Torgler (2007), Kirchler (2007), Sandmo (2012), Slemrod and Weber (2012), and Alm (2012).
} 
the expectation operator and utility $U(I)$ is a function only of income. This optimization proceeds using standard methods.

This economics-of-crime approach gives the sensible result that compliance depends upon enforcement, as represented by the audit and penalty rates. Indeed, it is straightforward to show with comparative statics analysis that declared income increases with an increase either in the probability of detection or in the penalty rate.

However, there are several troubling implications of this approach. The most serious of these implications is that the portfolio approach concludes not simply that enforcement matters in an individual's decision to pay taxes, but that enforcement is the only thing that matters. However, it is clear to many observers (Frey, 1997; Torgler, 2007; Kirchler, 2007) that compliance cannot be explained entirely by such purely financial considerations, especially those generated by the level of enforcement. The percentage of individual income tax returns that are subject to a thorough tax audit is generally quite small in most countries, almost always well less than 1 percent of all returns. Similarly, the penalty on even fraudulent evasion seldom exceeds more than the amount of unpaid taxes, and these penalties are infrequently imposed; civil penalties on non-fraudulent evasion are even smaller. A purely economic analysis of the evasion gamble suggests that most rational individuals should either underreport income not subject to source withholding or overclaim deductions not subject to independent verification because it is extremely unlikely that such cheating will be caught and penalized. However, even in the least compliant countries evasion seldom rises to levels predicted by a purely economic analysis, and in fact there are often substantial numbers of individuals who apparently pay all (or most) of their taxes all (or most) of the time, regardless of the financial incentives they face from the 
enforcement regime. $^{2}$

The portfolio model of individual compliance behavior therefore implies that a rational individual (especially one whose income is not subject to third-party sources of information) should report virtually no income. Although compliance varies significantly across countries (and across taxes) and is often quite low, compliance seldom falls to a level predicted by the standard economic theory of compliance. ${ }^{3}$

In the face of these difficulties, economists have pursued several strategies. One is to introduce additional theoretical considerations, still within the economics-of-crime model and still with the focus on individual motivations. For example, there are numerous theoretical extensions that include: expanding individual choices (e.g., labor supply occupational choice, sectoral choice, avoidance strategies); introducing alternative penalty, tax, and tax withholding functions; incorporating complexity and uncertainty about the relevant fiscal parameters; allowing the use of paid preparers; giving individuals positive rewards for honesty; and allowing systematic audit selection rules in which the tax authority uses information from the tax returns to determine strategically whom to audit. These extensions add necessary realism to the basic model (and complexity to its analysis). However, they do not resolve the basic dilemma of the standard economics-of-crime approach; that is, they leave enforcement as the main factor that motivates compliance, with all of the problems associated with this conclusion.

Other extensions also keep the focus on individual motivations but incorporate notions of individual behavior considered explicitly by other social sciences. Many of these can be

\footnotetext{
2 For a somewhat contrary view, see Slemrod (2007) and more recently Kleven et al. (2011).

3 There are other problems as well. For example, the deterrent effects of audits and fines are often present in empirical and experimental studies, but are typically small and transitory. The comparative statics effect of a change in the tax rate is also problematic: the theory suggests that an increase in the tax rate increases reported income, contrary to intuition and evidence.
} 
discussed under the rubric of behavioral economics, broadly defined as an approach that uses methods and evidence from other social sciences (especially psychology) to inform the analysis of individual decision making (and, as I discuss later, group decision making). The underlying motivation for the introduction of behavioral economics insights is dissatisfaction with the standard economic approach to analyzing individual behavior. The standard neoclassical economic model of human behavior is based on several main assumptions: that individuals are rational, that they have unlimited willpower, and that they are purely self-interested. While these assumptions may be a useful starting point for the analysis of individual behavior, there is much accumulating evidence that they are inaccurate and unrealistic depictions of many, perhaps most, individuals. Behavioral economics uses "departures" from the standard assumptions as the starting point for developing more realistic theories of individual behavior.

These theories are now being applied to tax evasion, along several dimensions. ${ }^{4}$ One strand deals mainly with individual behavior, and applies various formalizations of non-expected utility theory to these individual choices. There are numerous examples of these non-expected utility theories, including (but not limited to): prospect theory, rank dependent expected utility theory, first order and second order risk aversion, regret theory, disappointment theory, nonadditive probabilities, and ambiguity theory. Relative to expected utility theory, these models can generate predicted levels of compliance that better approximate observed levels (especially if they allow for overweighting of probabilities and for alternative reference points).

However, these models often retain their emphasis on individual motivations, thereby omitting what I believe are some essential elements. In the next section I discuss another strand

\footnotetext{
${ }^{4}$ For a survey of these theoretical developments as applied to tax evasion, see Myles, Tran-Nam, and Hashimzade (2013). For general discussions in other areas of behavior, see Camerer, Loewenstein, and Rabin (2004) and McCaffery and Slemrod (2006).
} 
of behavioral economics that deals more with social interactions. I also discuss several other approaches that incorporate group motivations in the compliance decisions of individuals.

\section{Introducing Group Motivations}

There are many ways of introducing group motivations into the analysis of tax compliance. In this section I discuss several of these approaches.

The starting point here is to be more precise on what is a group; put differently, who are the actors in the field? As I discuss in detail in other work (Alm et al., 2012), these actors include taxpayers, elected government officials (or government), tax authorities (e.g., the tax administration), and tax accountants. At the center are of course taxpayers. I focus mainly on interactions between taxpayers, recognizing of course that these taxpayer-taxpayer interactions are defined by the broader environment that is shaped by all of the actors.

\subsection{Via Public Good Provision}

The standard portfolio model of individual behavior ignores the uses to which tax payments may be put. However, taxes are used to finance a range of government services, especially public goods like national defense, parks, and infrastructure. Economists have long argued that the private provision of a public good will be inefficiently low because each individual will have an incentive to free ride on the private purchases of others. Because a public good is non-exclusive, an individual who does not contribute to its provision cannot be excluded from its use; because all individuals face this same incentive, individuals will not voluntarily contribute to public good provision. Put differently, public goods create a or a social contribution dilemma in which individual gain runs contrary to the collective good (Dawes, 1980).

However, there is also much work that argues that voluntary provision of a public good 
may not always play as a prisoners' dilemma game (Ledyard, 1995). This possibility arises especially when an individual's optimal decision depends upon the actions that he or she expects others to follow, both now and in the future. Under some circumstances, full voluntary contributions (or cooperation) may be the dominant individual strategy. This work therefore suggests that individuals pay taxes (voluntarily) because they value the goods provided by government and they recognize that their payment may be necessary to get others to contribute.

The presence of a public good that is financed from individuals' taxes can be readily incorporated in the standard portfolio model. All that is required is the addition to both $I_{C}$ and $I_{N}$ of a term that represents the monetary value of the public good financed by total group taxes. For each individual $i$, this term equals $\left[m s t\left(\sum_{j \neq i} R_{j}+R_{i}\right)\right]$, where total group taxes (or $\sum_{j \neq i} R_{j}+R_{i}$ ) equal the amount paid by individual $i$ (or $R_{i}$ ) plus the amount paid by all other $j$ members of the group other than individual $i$ (or $\sum_{j \neq i} R_{j}$ ), $m$ is a group surplus multiplier that is applied to the group's total taxes in order to capture the consumers' surplus derived from a public good, and $s$ is the share of individual $i$ in the resulting public good. It is readily shown that individual $i$ is more likely to pay taxes the higher is $m$, the higher is $s$, and the higher is $\left(\sum_{j \neq i} R_{j}\right)$.

\subsection{Via Behavioral Economics}

Several other types of taxpayer-taxpayer interactions emerge from behavioral economics. There is abundant evidence that individuals are influenced by the social context in which, and the process by which, decisions are made and that they are motivated not simply by self-interest but also by group notions like social (or group) norms, social capital, social customs, social networks, fairness, trust, reciprocity, intrinsic motivation, or tax morale, as well as by individual notions of guilt, shame, morality, or altruism. In short, individuals are not always the rational, 
outcome-oriented, self-controlled, selfish, and egoistic consumers envisioned by much of our standard theory. I call this latter strand of behavioral economics social interactions theory. In particular and building on work in the psychology of taxation (Lewis, 1982; Kirchler, 2007), there is much evidence of what may be termed a social norm of tax compliance (Elster, 1989). Although difficult to define precisely, a social norm can be distinguished by the feature that it is process-oriented, unlike the outcome-orientation of individual rationality. A social norm therefore represents a pattern of behavior that is judged in a similar way by others and that is sustained in part by social approval or disapproval. If others behave according to some socially accepted mode of behavior, then the individual will behave appropriately; if others do not so behave, then the individual will respond in kind. The presence of a social norm is also consistent with a range of other approaches that incorporate similar notions. ${ }^{5}$

This factor suggests that an individual will comply as long as he or she believes that compliance is the social norm (however defined); conversely, if non-compliance becomes pervasive, then the social norm of compliance disappears. More broadly, this last factor suggests that the nature of one's social interactions with others affects one's own compliance decision.

There are many ways in which behavioral notions relating to a social norm can be introduced. I present three such approaches.

Introducing a Reference Point. Perhaps the simplest way is suggested by the work of Kahneman and Tversky (1979), who incorporate what they term a reference point as a form of

\footnotetext{
${ }^{5}$ For example, Schmölders (1960) argues that individuals have an intrinsic motivation to cooperate. Frey (1997) suggests that compliance depends upon an individual's tax morale. Kirchler, Hoelzl, and Wahl (2008) explore the interaction between enforcement effort (power) and facilitation (trust) on the part of the tax authority via a slippery slope framework. McBarnet (2004) suggests that people may choose to comply willingly (what she terms committed compliance), they may choose to comply unwillingly (capitulative compliance), they may take full advantage of the law in minimizing their taxes (creative compliance), or they may choose non-compliance. Braithwaite (2009) argues that individuals differ in their motivations to comply with tax law, and she identifies both positive (deference) and negative (or defiance) motivations. There are of course still other approaches.
} 
social norm in their prospect theory by assuming that an individual suffers a loss in utility if he or she does not achieve some given level of utility defined by the reference point. The social norm may be achieved by reporting all income and paying all taxes; an individual who declares less than full income and pays less than full taxes suffers a loss in utility.

More formally, assume that each individual $i$ is suffers a psychological loss in expected income proportional to undisclosed taxes, equal to $\left[\gamma_{i} t\left(I_{i}-R_{i}\right)\right]$, where the coefficient $\gamma_{i}$ measures as a fraction how much individual $i$ would pay to avoid the loss associated with each dollar of unreported taxes. It is straightforward to demonstrate that an individual is more likely to report more income in the presence of this psychological loss, and that reported income increases with an increase in $\gamma_{i}$. Clearly, $\gamma_{i}$ is likely to be sensitive to the social norm of tax compliance. The stronger is the social norm, the more deviant the behavior of a non-compliant individual becomes, and the more loss the individual feels.

Introducing Extreme Risk Aversion. Another potentially fruitful modification is the incorporation of extreme forms of risk aversion, such as rank dependent expected utility (Bernasconi, 1998). For individuals described by a rank dependent expected utility model, expected utility can be modified to $E U_{t}\left(I_{i}\right)=g_{i} p U_{t}\left(I_{C}\right)+\left(1-g_{i}\right)(1-p) U_{t}\left(I_{N}\right)$, where the parameter $g_{i}$ serves to overweight the probability of the "bad" outcome (or detection and punishment) for individual $i$. This formulation can be shown to generate higher levels of compliance than the standard model. The use of a probability weighting function gives similar results, in which the probability $p$ is replaced with a weighting function $\pi_{t}(p)$ that depends positively upon the probability but that overweights low probabilities and underweights high ones.

Introducing Ethics and Morality. The notions of ethics and morality are related notions that refer to conceptions of right and wrong, as normative guides to conduct that are (or should 
be) important in shaping behavior. These terms are often used interchangeably. Even so, it is generally accepted that there are distinctions between them (McCloskey, 2006). Morality is now sometimes restricted to mean individual behavior that conforms to principles of individual conduct that are based on one's duty or obligation, while ethics is reserved for a more general approach to practical reasoning (thereby avoiding the separation of moral considerations from other practical considerations). Accordingly, there are two ways of introducing these notions, one that relies upon morality and one that focuses more on ethics.

A first approach utilizes the Akerlof and Kranton (2010) notion of one's ideal, or moral, behavior, defined in terms of "exemplary characteristics and behavior associated with a social category". Here a moral individual is one who considers paying taxes as the ethical norm; if the individual behaves differently, then he or she may incur a psychic cost, and may also feel pleased if there is full compliance for doing "the right thing". An amoral individual has an ideal behavior that may not be to comply fully with taxes, and indeed he or she may feel happy with noncompliant behavior. This approach implies that every individual has two different components in his or her utility function. The first part is the standard expected utility, as in the Allingham and Sandmo (1972) formulation. The second part is called the moral identity utility (Akerlof and Kranton, 2010), which is the gain or loss in utility from conforming or not to an individual's ideal behavior. This part of utility is denoted $\theta_{\mathrm{i}}\left(\mathrm{R}_{\mathrm{i}}{ }^{*}-\mathrm{R}_{\mathrm{i}}\right)$, where $\theta_{\mathrm{i}}$ is the moral utility or preference coefficient, $R^{*}$ is the ideal moral behavior that individual $i$ wants to follow (dependent on the category to which the individual belongs), and $R_{\mathrm{i}}$ is again declared income. The moral identity utility is a function of the difference between what the individual considers ideal behavior $R^{*}{ }_{\mathrm{i}}$ and the actual behavior $R_{\mathrm{i}}$. This ideal behavior $R^{*}{ }_{\mathrm{i}}$ is assumed to equal to $I_{i}$ (i.e., full income) for moral individuals, while it is less than $I_{i}$ for amoral individuals. Thus, if an 
individual does less than the morally ideal behavior, then the moral identity and the resulting utility are affected negatively, a negative effect that can be considered a feeling of guilt or frustration that is independent of tax evasion being detected. If actual behavior approaches the morally ideal behavior, then the individual may feel happy for doing what he or she thinks it is right. The resulting total expected utility $E U^{T}{ }_{i}$ of individual $i$ is a convex combination of the expected utility of Allingham and Sandmo (1972) and the moral identity utility of Akerlof and Kranton (2010), or $E U^{T}{ }_{i}=E U_{i}\left(I_{i}\right)-\theta_{i}\left(R^{*}{ }_{\mathrm{i}}-R_{i}\right)$. A moral individual who maximizes $E U^{T}{ }_{i}$ will report more income than in the standard Allingham and Sandmo (1972) approach.

A second approach is perhaps more straightforward. Here an additional element is introduced in the individual's utility function, an element that incorporates the individual's selfperception of ethically motivated behavior. The utility of any individual $i$ now becomes $U_{i}=U_{i}\left(I_{i}\right.$, $\left.M_{i}\right)$, where the term $M_{i}$ is a measure of this ethical self-perception when translated into individual morality . One potentially productive way of defining $M_{i}$ is in terms of the deviation of actual declared taxes from the level with full compliance. Here the individual views paying taxes as the normal, accepted, and ethical form of moral behavior, so that $M$ becomes a function of this difference. For example, in the specific function $M_{i}=M_{i}\left(t R_{i}-t I_{i}\right)=-\alpha_{i}\left(t R_{i}-t I_{i}\right)^{2}$, the term $M_{i}$ reaches a maximum (at zero) when $R_{i}=I_{i}$, or when the individual pays all legally due taxes, and $M_{i}$ is a minimum when $R_{i}=0$. This ethical self-perception also increases at a decreasing rate with declared income. ${ }^{6}$

\section{Finding EvidenCe for Group Motivations}

\footnotetext{
${ }^{6}$ In related approaches, Gordon (1989) adds an individual's honesty characteristic, which acts as a private psychic cost and which affects evasion negatively, and Erard and Feinstein (1994) offer a model with moral sentiments of guilt and shame when evasion is chosen.
} 
Here I present several types of evidence from my own work that demonstrates the importance of group motivations in individual compliance behavior.

\subsection{Using Empirical Methods}

Empirical Evidence on Tax Morale. One set of empirical studies relies mainly on survey information on taxpayer attitudes. In Alm and Torgler (2006), we use World Values Survey data that contain information on individuals in a wide range of countries over several different years of data. Our intention is to demonstrate the important role of culture differences across countries as determinants of an individual's attitude toward paying taxes. Our findings indicate a significantly higher tax morale in the United States than in Spain, controlling in a multivariate analysis for additional variables. When we extend our analysis to 14 European countries, our results again indicate that individuals in the United States have the highest tax morale across all countries, followed by Austria and Switzerland. Other survey-based empirical studies by Alm, Martinez-Vazquez, and Torgler (2006) and Alm and Gomez (2008) demonstrate similar effects of culture on tax morale in other countries.

Empirical Evidence on Interdependence. In other empirical work I examine compliance behavior more directly. In Alm and Yunus (2009), we examine directly whether an individual's compliance behavior depends at least in part on the decisions of others. Empirically, this channel can be examined via the spatial dependence (or interdependence) across all taxpayers in their compliance decisions. Spatial dependence can emerge in several ways. An obvious source of interdependence may be due to a social norm of compliance. Another source is that individuals typically exchange their experiences with others, so that they influence and are influenced by the tax evasion behavior of other taxpayers. Further, if one taxpayer successfully evades because he or she is not audited, then (given the limited audit resources available to the tax administration) 
this may increase the probability that another taxpayer will be audited. Finally, individuals may look to others to infer satisfactory policies, so that interdependence may come simply from imitating others, perhaps through social networks.

In Alm and Yunus (2009), we test for spatial dependence in the context of the U.S. federal individual income tax evasion. We use state-level, time-series, cross-section data for the years 1979 to 1997 , to estimate the factors that affect annual per return evasion in the individual income tax. We find that there is strategic interaction among neighboring states in the determination of individual income tax evasion, so that more evasion in a neighboring state is associated with more evasion in the own state. In terms of an elasticity, the response to a 10 percent increase in individual income tax evasion in a neighboring state results in an increase of 2.4 percent in the own state's individual income tax evasion. Our results also show a large deterrent effect from greater audit rates.

Empirical Evidence on Social Capital. In Alm, Clark, and Leibel (2012), we also examine direct evidence on taxpayer compliance behavior. Here we use previously unreleased data provided by the IRS to examine the determinants of tax filing compliance in the United States, using county level data for the tax year 2000. With access to these data, we are able to estimate known non-filing rates for almost all 3140 counties of the United States, and can therefore examine the determinants of non-filing rates at the county level, while controlling for other relevant factors.

We include explanatory variables identified in the standard compliance framework, including an enforcement index for identified non-filers, the audit rate of filers, and the average penalty rate for both filers and non-filers. Importantly, we also examine the role of social capital (or the institutions, norms, and networks that promote cooperation and enable collective action) 
on tax compliance. In particular, we test whether heterogeneity in household income, language, race, or religion, all commonly used measures of social capital, can explain variation in filing rates. We find that non-filing is increasing in heterogeneity by race, though not income or language, and decreasing in heterogeneity by religion. We also find that non-filing rates tend to fall with increases in the various enforcement variables.

\subsection{Using Experimental Methods}

Experimental Evidence on Public Good Provision. In Alm, McClelland, and Schulze (1992), we demonstrate that the presence of a public good financed by voluntary tax payments increased subject tax compliance significantly but in a nonlinear manner. We start with a standard experimental design: student subjects receive income, pay taxes on income voluntarily reported, and face some chance that underreported taxes will be detected and penalized. Importantly, we also introduce a public good; that is, subjects face each of three different levels of the group surplus multiplier $(m)$ for 15 rounds each, with $m$ equal to 0,2 , and 6 . We find that compliance increases with increases in the group surplus multiplier. When $m=0$, so that subjects receive nothing for their tax payments, the average group compliance rate equals 43.5 percent. The treatment in which $m=2$ generates an even higher average group compliance rate $(53.7$ percent). An increase in the multiplier to 6 increases compliance further but only to 59.2 percent and not to full compliance.

Experimental Evidence on Fiscal Exchange. Other experimental work examines the role of social institutions and processes as they work through public good provision. In Alm, Jackson, and McKee (1993), we examine how an individual's reporting decisions are affected by various aspects of their social interactions via fiscal exchange. We again start with a standard experimental design: individuals receive income, pay taxes on income voluntarily reported, and 
face some chance that underreported taxes will be detected and penalized. We then extend the design. In some treatments subjects must choose among two alternative types of public goods, with the type of public good decided by majority vote; in other treatments, the subjects are not allowed to vote on public good provision, and the public good is instead imposed on the group. The level of support for the public good alternatives also varies. In some treatments group members strongly prefer one of the alternative public good types; the level of support for the two alternatives is more evenly divided in other treatments.

Our results indicate that both the manner in which group decisions are made and the level of popular support for the public goods over which these other dimensions of public good provision affect compliance. Compliance is significantly higher when individuals vote on the use of their taxes than when the identical result is imposed upon them. Compliance is also higher when the vote is decisive than when the vote is close. Finally, compliance is significantly lowered by the imposition of an unpopular expenditure program; indeed, compliance is lower with an imposed and unpopular public good than in the complete absence of any public good.

Experimental Evidence on Voting and Social Norms. In Alm, McClelland, and Schulze (1999), we also examine the impact on compliance of voting on various aspects of the fiscal system. Our underlying premise is that the existence of a social norm affects an individual's decisions on tax compliance, and that voting can in turn affect this social norm (and so compliance). Subjects start the experiment facing a given level of the tax rate, the fine rate, and the audit rate. After 10 rounds, one of these parameters is changed, and subjects face the new level for another 10 rounds in order to gain experience with the new parameter. Subjects then vote via majority rule with secret ballots on different aspects of the fiscal system that they face, where the vote is always on only two alternative levels of a single parameter (e.g., the tax rate, the audit rate, the fine rate). 
Subjects then face the fiscal system selected by the group vote for a final 10 rounds. We observe the votes, and also compliance behavior before and after the votes.

Our experimental results are consistent with a central role for social norms in tax compliance behavior. In all sessions, individual compliance behavior after the vote is announced is decidedly different from the pre-vote behavior under the identical fiscal regime. Of particular interest, when the group rejects any attempt to raise the level of enforcement, compliance always falls, often collapsing virtually to zero. These results suggest that the group decision to reject greater enforcement ratifies and justifies any individual tendency to evade taxes. Put differently, the group decision on enforcement destroys any pre-vote social norm of tax compliance, and, in the absence of the social norm, post-vote compliance disappears.

However, our results also suggest that the social norm of tax compliance can be affected by group communication. In several sessions, subjects are allowed to communicate before a vote is taken. After this "cheap talk", subjects support a greater level of enforcement, in contrast to their rejection of greater enforcement in those sessions in which cheap talk was not allowed. Indeed, the post-vote level of reporting with cheap talk approaches full compliance. It is as if the cheap talk, in combination with the vote, changes the social norm of tax compliance so that paying taxes is now the accepted mode of behavior.

\section{Experimental Evidence on Information Provision and Dissemination. Another} experimental study examines the impact of information provision on compliance (Alm, Jackson, and McKee, 2009). In the base case sessions, participants receive no information about audit results beyond their own audit experience. In a second treatment the same objective audit rates are in effect, and participants have additional information as they are told by the experimenter the actual number of audits conducted and the fines collected during a period. In a third 
treatment the participants are offered the opportunity to send a "message" to the other participants about their audit experience; subjects may also choose to send no message, and participants may send a message that is truthful or not. The experimental design therefore tests hypotheses about the awareness of audit probabilities arising from two types of information dissemination regarding audit policies and results: official information disseminated by the tax authority, and informal or unofficial communications among taxpayers (or subjects).

We find that the responses to official and unofficial information vary across the regimes in ways that are consistent with the presence of a social norm of compliance. When unofficial messages from other taxpayers report substantial levels of compliance among taxpayers, individuals are more likely to comply in subsequent rounds; conversely, compliance declines when messages are consistent with widespread evasion.

Experimental Evidence on Peer Effects. Alm, Bloomquist, and McKee (2012) examine a similar issue using experimental methods. We argue that individuals are affected in their compliance behavior by the behavior of their "neighbors", or those about whom they may have information, whom they may know, or with whom they may interact on a regular basis. Individuals seem more likely to file and to report their taxes when they believe that other individuals are also filing and reporting their taxes; conversely, when individuals believe that others are cheating on their taxes, they may well become cheaters themselves.

In one setting, we inform individuals about the frequency that their neighbors submit a tax return. In a second setting, we inform them about the number of their neighbors who are audited, together with the penalties that they pay. In both cases, we examine the impact of information on filing behavior and also on subsequent reporting behavior. We find that providing information on whether one's neighbors are filing returns and/or reporting income has a 
statistically significant and economically large impact on individual filing and reporting decisions. However, this "neighbor" information does not always improve compliance, depending on the exact content of the information.

Experimental Evidence on Sympathy and Empathy. In a final experimental study, Alm and Calvet (2013) examine the effects of morality on individual compliance behavior. We focus on two moral emotions, sympathy and empathy. Empathy is an affective state of "putting yourself in someone else's shoes", in which an individual feels the same or a similar emotion as the other person. Sympathy is considered an emotional response of sorrow or concern for another's wellbeing caused by the other's emotional state, a response that is not identical to the other's emotion. We include these notions in order to examine the effects of morality on tax compliance via an individual's moral identity.

We run a series of laboratory experiments in which we observe the subjects' decisions in a series of one-shot tax compliance games. Each session starts with general instructions on basic experimental procedures. Then, subjects play a standard tax compliance game. Each session concludes with a questionnaire used to elicit information on the subjects, including the frequency of prosocial behaviors (e.g., blood donation, giving to the homeless or to a charity, volunteering) and the Davis Empathic Concern Scale (DECS) that measures different aspects of sympathy. Finally, one session includes a priming activity designed to generate feelings of empathy in a group of subjects before they face tax compliance decisions, by asking subjects to write in their own words the definition of the Golden Rule after reading versions in six different religions; following this priming, the subjects complete the tax compliance pat of the experiment. In all other sessions, subjects do not complete the priming task. Accordingly, our use of the DECS and questions about frequency of prosocial behaviors allows us to identify subjects' sympathy; our 
priming activity allows us to promote empathy.

Our results indicate that the presence of sympathy encourages more tax compliance. Our results also suggest that priming to elicit empathy has a positive impact on compliance.

\section{Conclusions}

The more basic and core lessons from this research are, I believe, relatively simple:

- Individuals are influenced by narrowly defined financial considerations, by their cognitive limitations, and by a social norm of behavior, however defined and determined; that is, individuals are affected by individual and group motivations.

- Individuals cannot be represented by a single representative agent, but must be considered a collection of different segments.

- Government deals with individuals via its enforcement activities, its ability to ensure that individuals trust its actions, and its provision of goods and services to individuals.

Is it possible to construct a theory that incorporates all of these different perspectives, one that includes both individual motivations and group motivations in a comprehensive theory of tax compliance? Such an endeavor seems quite unlikely. However, even if such a general theory proves illusive, I believe that there are many productive avenues by which research can proceed.

First, it is essential that the theoretical modeling of individual behavior continue. It is through such analyses that a better understanding of individual motivations emerges. Even so, it is also essential that we recognize and accept that one theory may not fit all individuals at all times, or even the same individual at different times. Individuals in their infinite variety exhibit a "full house" of behaviors, behaviors that cannot be neatly captured by a single theory.

What types of individual behavior remain unexamined? The ways in which reciprocity (i.e., responding to a positive action with another positive action, responding to a negative action with another negative action) might influence compliance behavior is largely unexamined, even 
though its impact on other dimensions of behavior (e.g., voluntary provision of public goods) has been the subject of much work (Cox, 2012). Similarly, the effects of altruism (i.e., a willingness to act in the interests of others) on charitable donations are well-known (Andreoni, 1989), but again its impact on compliance is largely unexamined. The impacts of different notions of equity (Young, 1994; Fehr and Schmidt, 1999; Bolton and Ockenfels, 2000) have also been increasingly examined, but to date these analyses have largely ignored tax compliance. It is via theory that these impacts can best be developed. Especially promising lines of research include the effects of shame and of perceptions of justice on compliance.

Second and consistent with the central theme of this paper, I believe that the focus will shift away from modeling individual behavior to modeling group behavior, including the evolution over time of aggregate behavior (e.g., the dynamics). It is here where the development of individual theories is especially useful.

Third and finally, testing these theories will require much creativity. Laboratory experiments seem likely to continue to play a decisive role in testing (and even in developing) these individual theories. Controlled field experiments are also a promising avenue of testing individual theories. Given the complexity of many of these theories, especially in their aggregate form, tests of such aggregate behavior will necessarily be forced to use numerical simulation methods. Agent-based models seem likely to emerge as a leading tool here.

In sum, we have learned much about tax compliance in the years since Allingham and Sandmo (1972) provided the still-relevant framework for its rigorous analysis. Even so, there remain major gaps in our understanding, all of which require further research efforts in measuring, explaining, and controlling its patterns. 


\section{References}

Akerlof, G. A. \& Kranton, R. E. (2010). Identity Economics: How Our Identity Shape Our Work, Wages amd Well-being. Princeton, NJ: Princeton University Press.

Allingham, M. G., \& Sandmo, A. (1972). Income tax evasion: A theoretical analysis. Journal of Public Economics, 1 (3-4), 323-338.

Alm, J. (2012). Measuring, explaining, and controlling tax evasion: Lessons from theory, field studies, and experiments. International Tax and Public Finance, 19 (1), 54-77.

Alm, J., Bloomquist, K., \& McKee, M. (2012). When you know your neighbor pays taxes: Information, peer effects, and tax compliance. Tulane University Working Paper. New Orleans, LA.

Alm, J., \& Calvet, R. (2013). Empathy, sympathy, and tax compliance. Journal of Economic Psychology, forthcoming.

Alm, J., Clark, J., \& Leibel, K. (2012). Socio-economic diversity, social capital, and tax filing compliance in the United States. Tulane University Working Paper, New Orleans, LA.

Alm, J., \& Gomez, J. L. (2008). Social capital and tax morale in Spain. Economic Analysis and Policy, 38 (1), 73-87.

Alm, J., Jackson, B. R., \& McKee, M. (1993). Fiscal exchange, collective decision institutions, and tax compliance. Journal of Economic Behavior and Organization, 22 (4), 285-303.

Alm, J., Jackson, B. R., \& McKee, M. (2009). Getting the word out: Increased enforcement, audit information dissemination, and compliance behavior. Journal of Public Economics 93 (3-4), 392-402.

Alm, J., Kirchler, E., Muehlbacher, S., Gangl, K., Hofmann, E., Kogler, C., \& Pollai, M. (2012). Rethinking the research paradigms for analyzing tax compliance behaviour. CESifo Forum, 13 (2), 33-40.

Alm, J., Martinez-Vazquez, J., \& Torgler, B. (2006). Russian attitudes toward paying taxes before, during, and after the transition. International Journal of Social Economics, 33 (12), 832-857.

Alm, J., McClelland, G. H., \& Schulze, W. D. (1992). Why do people pay taxes? Journal of Public Economics , 48 (1), 21-38.

Alm, J., McClelland, G. H., \& Schulze, W. D. (1999). Changing the social norm of tax compliance by voting. Kyklos, 52 (2), 141-171.

Alm, J., \& Torgler, B. (2006). Culture differences and tax morale in the United States and in Europe. Journal of Economic Psychology, 27 (2), 224-226.

Alm, J., \& Yunus, M. (2009). Spatiality and persistence in U.S. individual income tax compliance. National Tax Journal, 62 (1), 101-124.

Andreoni, J. (1989). Giving with impure altruism: Applications to charity and Ricardian Equivalence. The Journal of Political Economy, 97 (6), 1447-58.

Bernasconi, M. (1998). Tax evasion and orders of risk aversion. Journal of Public Economics 67 (2), 123-134.

Bolton, G. E., \& Ockenfels, A. (2000). ERC: A theory of equity, reciprocity, and competition. The American Economic Review, 90 (1), 166-193.

Braithwaite, V. (2009). Defiance in Taxation and Governance - Resisting and Dismissing Authority in a Democracy. Cheltenham, UK and Northhampton, MA: Edward Elgar 
Publishing.

Camerer, C. F., Loewenstein, G. F., \& Rabin, M. (Eds.) (2004). Advances in Behavioral Economics. Princeton, NJ: Russell Sage Foundation and Princeton University Press.

Cox, J. C. (2012). Private goods, public goods, and common pools with Homo Reciprocans. Southern Economic Journal, 79 (1), 1-14.

Dawes, R. M. (1980). Social dilemmas. Annual Review of Psychology, 31 (2), 169-193.

Erard, B., \& Feinstein, J. S. (1994). The role of moral sentiments and audit perceptions in tax compliance. Public Finance, 49 (1), 70-89.

Elster, J. (1989). The Cement of Society - A Study of Social Order. Cambridge, UK: Cambridge University Press.

Fehr, E., \& Schmidt, K. M. (1999). A theory of fairness, competition, and cooperation. The Quarterly Journal of Economics, 114 (3), 817-868.

Frey, B. (1997). Not Just For the Money - An Economic Theory of Personal Motivation. Cheltenham, United Kingdom: Edward Elgar Publishing Limited.

Gordon, J. P. F. (1989). Individual morality and reputation costs as deterrents to tax evasion. European Economic Review, 33 (4), 797-805.

Kahneman, D., \& Tversky, A. (1979). Prospect theory: An analysis of decision under risk. Econometrica, 47 (2), 263-292.

Kirchler, E. (2007). The Economic Psychology of Tax Behavior. Cambridge, UK: Cambridge University Press.

Kirchler, E., Hoelzl, E., \& Wahl, I. (2008). Enforced versus voluntary tax compliance: The "slippery slope" framework. Journal of Economic Psychology, 29 (2), 210-225.

Kleven, H. J., Knudsen, M. B., Kreiner, K. T., Pedersen, S., \& Saez, E. (2010). Unwilling or unable to cheat? Evidence from a randomized tax audit experiment in Denmark. Econometrica, 79 (3), 651-692.

Ledyard, J. O. (1995). Public goods: A survey of experimental research. In The Handbook of Experimental Economics, J. H. Kagel and A. E. Roth (Eds.). Princeton, NJ: Princeton University Press, 111-194.

Lewis, A. (1982). The Psychology of Taxation. Oxford, UK: Martin Robertson.

McBarnet, D. (2004). Crime, Compliance, and Control. Burlington, VT: Ashgate/Dartmouth Publishers Ltd.

McCaffery, E. J., \& Slemrod, J. (Eds.) (2006). Behavioral Public Finance. New York, NY: Russell Sage Foundation.

McCloskey, D. N. (2006). The Bourgeois Virtues: Ethics for an Age of Commerce. Chicago, Il and London, UK: University of Chicago Press.

Myles, G., Tran-Nam, B., \& Hashimzade, N. (2013). New approaches to the economics of tax evasion. Journal of Economic Surveys, forthcoming.

Sandmo, A. (2012). An evasive topic: Theorizing about the hidden economy. International Tax and Public Finance, 19 (1), 5-24.

Schmölders, G. (1960). Das Irrationale in der Offentlichen Finanzwirtschaft [The Irrational in Public Finance]. Frankfurt am Main, Germany: Suhrkamp.

Schneider, F., \& Enste, D. H. (2002). The Shadow Economy - An International Survey. Cambridge, MA: Cambridge University Press.

Slemrod, J. (2007). Cheating ourselves: The economics of tax evasion. The Journal of Economic Perspectives, 21 (1), 25-48. 
Slemrod, J., \& Weber, C. (2012). Evidence of the invisible: Toward a credibility revolution in the empirical analysis of tax evasion and the informal economy. International Tax and Public Finance, 19 (1), 25-53.

Torgler, B. (2007). Tax Compliance and Tax Morale: A Theoretical and Empirical Analysis.

Cheltenham, UK: Edward Elgar Publishing.

Young, H. P. (1994). Equity: In Theory and Practice. Princeton, NJ: Princeton University Press. 